\title{
Simulation of Bubbling Fluidized Bed using a One-Dimensional Model Based on the Euler-Euler Method
}

\author{
Cornelius Agu* Marianne Eikeland Lars Tokheim Britt Moldestad \\ Department of Process, Energy and Environmental Technology \\ University College of Southeast Norway, Norway, \{Cornelius.e.agu, Marianne.Eikeland, \\ Lars.A.Tokheim, britt.moldestad\} dusn.no
}

\begin{abstract}
The behaviour of a fluidized bed can be modeled based on the Euler-Euler approach. This method has been fully utilized in both three-dimensional (3D) and twodimensional (2D) systems for obtaining, for example, the axial and radial distribution of fluidized bed properties. However, the bed property such as void fraction distribution along the flow direction can be of great interest for a design purpose. To save computational cost, an appropriate one-dimensional (1D) model can be used to obtain the average bed property along the vertical axis of a fluidized bed. In this paper, a 1D model based on the Euler-Euler method is presented. The results show that the model can be used to describe the behaviour of a fluidized bed. With a reasonable accuracy, the results also show that the 1D model can predict the minimum fluidization velocity and the superficial gas velocity at the onset of slugging regime.
\end{abstract}

Keywords: Euler-Euler, bubbling, void fraction, fluidized bed, flow regime

\section{Introduction}

The fluidized bed has wide industrial applications. Such applications include circulation of catalyst particles in a chemical reactor, pneumatic transport of particles and gasification of coal/biomass. In fluidized bed reactors, there is a good mixing of solids and fluid, and this enhances heat and mass transfer rates between the fluid and the particles.

For the purpose of design and prediction of hydrodynamic behaviour of fluid-particle systems, several empirical and semi-empirical models have been developed. Moreover, the computational fluid dynamics has also been applied in such a multi-phase system. As in a single-phase system, the mass, momentum and energy transfers also govern the motions of fluid and particles in the bed. The interface momentum transfer between the phases influences the behaviour of the system. When a fluid flows through a bed of particles, the drag force acts continuously against the weight of the bed. At a certain fluid velocity, the bed begins to float in the fluid stream. This velocity is generalized as the minimum fluidization velocity. Previous studies have shown that at this fluid velocity, the interphase drag force corresponds to the net weight of the bed. This concept is used in deriving models for estimating the minimum fluidization velocity from the drag models (Kunnii and Levenspiel, 1991). Due to complexities arising from particle-particle interactions and particlewall interactions, it has been proven difficult to establish accurate fluid-particle interphase drag models to predict accurately the behaviour of fluidized beds. However, a number of drag models can be found in the literature (Taghipour et al, 2005; Beuzarti and Bournot, 2012; Li et al, 2009).

Beyond the onset of bed fluidization, and with increasing superficial gas velocity, the agitation of particles in the bed increases. Different phase transitions can be observed when a bed is fluidized. As the fluid velocity increases, a fluidized bed passes through the bubbling regime, the turbulent regime, fast fluidization and the pneumatic conveying regime (Kunnii and Levenspiel, 1991).

In this study, the focus is on modelling a bubbling fluidized bed. A number of models have been developed for such a regime. Davidson and Harrison (1965) developed a simple two-phase model based on a mass balance and experimental observations. The underlying assumption in this model is that two distinct phases, bubble and emulsion exist throughout the bed. A more advanced model based on physics of mass, momentum and energy conservations have also been developed. Two widely used approaches to this model development are those based on the Euler-Euler and the EulerLagrange methods (Crowe et al, 2012). Depending on the fluid-particle drag model and the numerical method employed, the two- and three-dimensional (2D and 3D) versions of these models have been proven successful in predicting the behaviour of fluid-particle multiphase systems. One major drawback is that the $2 \mathrm{D}$ and $3 \mathrm{D}$ models are highly computational time demanding.

There is a limited number of studies based on a 1D model. Solsvik et al (2015) used a 1D model in a methane reforming studies, and Silva (2012) presented a non-conservative version of the model for simulating 
the bubbling bed behaviour of a biomass gasification process.

In this paper, the goal is to develop a detailed onedimensional model that predicts well the behaviour of a fluidized bed with less computational time. A 1D model based on the Euler-Euler approach is used to study the behaviour of glass bead particles in a bubbling bed. The simulated results are compared with experimental data obtained from a cold fluidized bed, and with the simulation results based on a three dimensional model. The simulated superficial gas velocity at the onset of slugging is compared with the result obtained from the correlation (Geldart, 1986).

\section{Computational Model}

\subsection{Governing Equations}

The governing equations for the motions of fluid and particles in a fluidized bed are developed based on the Euler approach, and are given in (1) - (5). In the following, the subscripts " $\mathrm{s}$ " and "g" denote solid and gas. $u$ and $v$ are the respective gas and particle velocities, $g$ is the acceleration due to gravity, $\beta_{\mathrm{d}}$ is the momentum transfer coefficient, and $P, \varepsilon$ and $\rho$ are the pressure, volume fraction and density, respectively. $f$ is the wall frictional factor.

\subsubsection{Continuity Equations}

$$
\begin{gathered}
\frac{\partial}{\partial t}\left(\varepsilon_{\mathrm{g}} \rho_{\mathrm{g}}\right)+\frac{\partial}{\partial z}\left(\varepsilon_{\mathrm{g}} \rho_{\mathrm{g}} u\right)=0 \\
\frac{\partial}{\partial t}\left(\varepsilon_{\mathrm{s}} \rho_{\mathrm{s}}\right)+\frac{\partial}{\partial z}\left(\varepsilon_{\mathrm{s}} \rho_{\mathrm{s}} v\right)=0 \\
\varepsilon_{\mathrm{g}}+\varepsilon_{\mathrm{s}}=1
\end{gathered}
$$

\subsubsection{Momentum Equations}

$\frac{\partial}{\partial t}\left(\varepsilon_{\mathrm{g}} \rho_{\mathrm{g}} u\right)+\frac{\partial}{\partial z}\left(\varepsilon_{\mathrm{g}} \rho_{\mathrm{g}} u \cdot u\right)=\frac{\partial}{\partial z}\left(\mu_{\mathrm{eg}} \frac{\partial \mathrm{u}}{\partial z}\right)-\varepsilon_{\mathrm{g}} \frac{\partial P_{\mathrm{g}}}{\partial z}-$

$\frac{2 f_{\mathrm{g}} \varepsilon_{\mathrm{g}} \rho_{\mathrm{g}} u|u|}{D_{h}}-\quad \varepsilon_{\mathrm{g}} \rho_{\mathrm{g}} g+\beta_{\mathrm{d}}(v-u)$

$\frac{\partial}{\partial t}\left(\varepsilon_{\mathrm{s}} \rho_{\mathrm{s}} v\right)+\frac{\partial}{\partial z}\left(\varepsilon_{\mathrm{s}} \rho_{\mathrm{s}} v \cdot v\right)=\frac{\partial}{\partial z}\left(\mu_{\mathrm{es}} \frac{\partial v}{\partial z}\right)-\varepsilon_{\mathrm{s}} \frac{\partial P_{\mathrm{g}}}{\partial z}-$

$\frac{2 f_{\mathrm{s}} \varepsilon_{\mathrm{s}} \rho_{\mathrm{s}} v|v|}{D_{h}}-\varepsilon_{\mathrm{s}} \rho_{\mathrm{s}} g-\frac{\partial P_{\mathrm{s}}}{\partial z}+\beta_{\mathrm{d}}(u-v)$

Here, $D_{h}=4 A / P_{\text {wet }}$ is the bed hydraulic diameter, where $A$ is the bed cross-sectional area and $P_{\text {wet }}$ is the wetted perimeter of the bed. $\mu_{\mathrm{es}}=2 \mu-\lambda$ is the phase equivalent dynamic viscosity. The solid pressure and solid stress due to collisions are based on the kinetic theory of granular flow. The constitutive equations of the model (1) - (5) are given in (6) - (10).

\subsubsection{Constitutive Equations}

- $\quad$ Gas phase (Gidaspow, 1994)

$$
f_{\mathrm{g}}=\left\{\begin{array}{cc}
16 R e_{\mathrm{g}}^{-1} ; \quad & R e_{\mathrm{g}} \leq 2300 \\
0.0791 R e_{\mathrm{g}}^{-0.25} ; & R e_{\mathrm{g}}>2300
\end{array}\right.
$$

- $\quad$ Solid phase (Gidaspow, 1994; Lathowers and Bellan, 2000)

$$
\begin{aligned}
& f_{\mathrm{s}}=0.048|v|^{-1.22} \\
& P_{\mathrm{s}}=K_{1} \varepsilon_{\mathrm{s}}^{2} \theta \\
& \lambda_{\mathrm{s}}=K_{2} \varepsilon_{\mathrm{s}} \sqrt{\theta} \\
& \mu_{\mathrm{s}}=K_{3} \varepsilon_{\mathrm{s}} \sqrt{\theta}
\end{aligned}
$$

where

$K_{1}=2(1+e) \rho_{\mathrm{s}} g_{0}$,

$K_{2}=\frac{4 d_{\mathrm{p}} \varepsilon_{\mathrm{s}} \rho_{\mathrm{s}} g_{0}(1+e)}{3 \sqrt{\pi}}-\frac{2}{3} K_{3}$,

$K_{3}=d_{\mathrm{p}} \rho_{\mathrm{s}} / 2\left[\frac{\sqrt{\pi}}{3(3-e)}\left\{1+0.4 \varepsilon_{\mathrm{s}} g_{0}(1+e)(3 e-1)\right\}+\right.$

$\left.\frac{8 \varepsilon_{\mathrm{s}} g_{0}(1+e)}{5 \sqrt{\pi}}\right]$,

$g_{0}=\frac{3}{2}\left[1-\left(\frac{\varepsilon_{\mathrm{s}}}{\varepsilon_{\operatorname{maxP}}}\right)^{1 / 3}\right]^{-1}$,

$\theta=\left[\frac{\left(\sqrt{\left(K_{1} \varepsilon_{\mathrm{s}}\right)^{2}+4 K_{4} \varepsilon_{\mathrm{s}}\left(K_{2}+2 K_{3}\right)}-K_{1} \varepsilon_{\mathrm{s}}\right)}{2 K_{4} \varepsilon_{\mathrm{s}}} \frac{\partial v}{\partial z}\right]^{2}$,

$K_{4}=12 \rho_{\mathrm{s}} g_{0}\left(1-e^{2}\right) /\left(d_{\mathrm{p}} \sqrt{\pi}\right)$.

Here, $\theta$ is the granular temperature, $g_{0}$ is the radial distribution function, $e$ is the coefficient of restitution and $d_{\mathrm{p}}$ is the single particle diameter. $\varepsilon_{\operatorname{maxP}}$ is the solid fraction at maximum packing with a value of about 0.7406. $\mu$ and $\lambda$ are shear and bulk viscosity, respectively.

\subsection{Drag Model}

There are number of drag models that can be found in literature. In this paper, the model proposed by Gidaspow (1994) is used.

$$
\beta_{\mathrm{d}}= \begin{cases}\beta_{\mathrm{dErg}} ; & \varepsilon_{\mathrm{g}} \leq 0.8 \\ \beta_{\mathrm{dWY}} ; & \varepsilon_{\mathrm{g}}>0.8\end{cases}
$$

Here, $\beta_{\mathrm{dErg}}$ and $\beta_{\mathrm{dErg}}$ are given by (12) and (13), respectively.

$$
\begin{gathered}
\beta_{\mathrm{dErg}}=150 \frac{\varepsilon_{\mathrm{s}}^{2} \mu_{\mathrm{g}}}{\varepsilon_{\mathrm{g}}\left(\emptyset_{\mathrm{s}} d_{\mathrm{p}}\right)^{2}}+1.75 \frac{\varepsilon_{\mathrm{s}} \rho_{\mathrm{g}}|u-v|}{\emptyset_{\mathrm{s}} d_{\mathrm{p}}} \\
\beta_{\mathrm{dWY}}=\frac{3}{4} C_{\mathrm{d}} \frac{\varepsilon_{\mathrm{s}} \varepsilon_{\mathrm{g}} \rho_{\mathrm{g}}}{\emptyset_{\mathrm{s}} d_{\mathrm{p}}}|u-v| \varepsilon_{\mathrm{g}}^{-2.65}
\end{gathered}
$$


where

$$
C_{\mathrm{d}}=\left\{\begin{array}{ll}
\frac{24}{R e_{\mathrm{p}}}\left(1+0.15 R e_{\mathrm{p}}^{0.687}\right) ; & R e_{\mathrm{p}}<1000 \\
0.44 ; & R e_{\mathrm{p}} \geq 1000
\end{array},\right.
$$

$R e_{\mathrm{p}}=\frac{\varepsilon_{\mathrm{g}} \rho_{\mathrm{g}}|u-v|}{\mu_{\mathrm{g}}} d_{\mathrm{p}}$.

$C_{\mathrm{d}}$ is the drag coefficient and $R e_{\mathrm{p}}$ is the particle Reynolds number. $\varnothing_{\mathrm{s}}$ is the single particle sphericity. To avoid discontinuity in using the above drag model, a weighting function proposed by Lathowers and Bellan (2000) is used.

$$
\begin{gathered}
\beta_{\mathrm{d}}=\left(1-\omega_{\mathrm{d}}\right) \beta_{\mathrm{dErg}}+\omega_{\mathrm{d}} \beta_{\mathrm{dWY}} \\
\omega_{\mathrm{d}}=\frac{1}{\pi} \tan ^{-1}\left(150 * 1.75\left(0.2-\left(1-\varepsilon_{\mathrm{g}}\right)\right)\right)+0.5
\end{gathered}
$$

\subsection{Void Fraction Equation}

Another crucial issue is the prediction of void fraction $\varepsilon_{\mathrm{g}}$ along the bed. It is obvious that neither (1) nor (2) can predict the void if used alone. This is due to the dependency of void fraction on the relative velocity between the solid particles and the fluid. In the computer code MFIX, the solid volume fraction is obtained based on a guess-and-correction method (Syamlal, 1998). Effective application of this method requires a known function of solid pressure with the solid volume fraction.

With the assumption that both solid particles and fluid have a constant density over the bed, the void fraction equation is established based on (1) and (2) (Gidaspow, 1994). However, due to changes of fluid pressure in the bed, there could be slight changes in the fluid density, which may influence the bed behaviour. In this paper, a new version of the void equation developed based on the continuity equations for gas and solid phases, is introduced. The new void equation, described below, partially accounts for the effect of fluid density variation.

$$
\alpha_{\mathrm{v}} \frac{\partial \varepsilon_{\mathrm{g}}}{\partial t}+v_{\mathrm{m}} \frac{\partial \varepsilon_{\mathrm{g}}}{\partial z}=\varepsilon_{\mathrm{s}} \varepsilon_{\mathrm{g}} \rho_{\mathrm{rg}} \frac{\partial v_{\mathrm{r}}}{\partial z}
$$

Here, $v_{r}=v-u$ is the relative velocity between the solid particles and the fluid. $v_{\mathrm{m}}$ and $\alpha_{\mathrm{v}}$ are mixture mass velocity and relative volume fraction, respectively, and are expressed as

$$
\begin{aligned}
& \alpha_{\mathrm{v}}=\varepsilon_{\mathrm{g}} \rho_{\mathrm{rg}}+\varepsilon_{\mathrm{s}}, \\
& v_{\mathrm{m}}=\varepsilon_{\mathrm{g}} \rho_{\mathrm{rg}} v+\varepsilon_{\mathrm{s}} u .
\end{aligned}
$$

where, $\rho_{\text {rg }}=\rho_{\mathrm{g}} / \rho_{\text {ref }}$ is the reduced gas density. The gas density is obtained, assuming the ideal gas behaviour, $\rho_{\mathrm{g}}=\frac{\mathrm{P}_{\mathrm{g}}}{R T}$.

\subsection{Minimum Fluidization Velocity}

The onset of fluidization occurs at a certain velocity where the net weight of the bed balances the drag force between the fluid and the bulk of particles in the bed. The minimum fluidization velocity, $U_{\mathrm{mf}}$ can be obtained from

$$
U_{\mathrm{mf}}=\frac{\mu_{\mathrm{g}}}{\rho_{\mathrm{g}} d_{\mathrm{p}}} R e_{\mathrm{p} . \mathrm{mf}} .
$$

The particle Reynolds number at minimum fluidization condition $R e_{\text {p.mf }}$ is based on the Ergun's bed pressure drop model (Ergun, 1952),

$$
150 \frac{\left(1-\varepsilon_{\mathrm{mf}}\right)}{\varepsilon_{\mathrm{mf}}^{3} \phi_{\mathrm{s}}^{2}} R e_{\mathrm{p} . \mathrm{mf}}+1.75 \frac{1}{\varepsilon_{\mathrm{mf}}^{3} \phi_{\mathrm{s}}} R e_{\mathrm{p} . \mathrm{mf}}^{2}=A r
$$

where $A r$ is the Archimedes number, expressed as

$$
A r=\frac{d_{p}^{3} \rho_{\mathrm{g}}\left(\rho_{\mathrm{s}}-\rho_{\mathrm{g}}\right) g}{\mu_{\mathrm{g}}^{2}} .
$$

Here, $\varepsilon_{\mathrm{mf}}$ is the bed void fraction at the minimum fluidization condition. $U_{m f}$ and $\varepsilon_{\mathrm{mf}}$ are bed properties, and either of them must be known for the other to be calculated from (19) - (21). A number of empirical correlations for $\varepsilon_{\mathrm{mf}}$ are available (Kunnii and Levenspiel, 1991), but this paper uses the correlation proposed by Wen and $\mathrm{Yu}(1966)$.

$$
\frac{1}{\emptyset_{\mathrm{s}} \varepsilon_{\mathrm{mf}}^{3}} \approx 14
$$

\section{Experimental setup}

The experimental setup consists of a vertical cylindrical column of height $1.4 \mathrm{~m}$ and base diameter $0.084 \mathrm{~m}$. The rig is fitted with ten pressure sensors, measuring the fluid pressure in the column up to the height of about 1.0 $\mathrm{m}$. Compressed air at ambient temperature is used as the fluidizing medium. The bottom of the column is fitted with a porous plate. The porous plate ensures even distribution of air within the bed.

Thapa and Halvorsen (2013) conducted experiments with this cold fluidized bed rig using glass beads particles (particle size $350 \mu \mathrm{m}$ ) at a bed height of 0.32 $\mathrm{m}$ (see Figure 1). The experimental data used in this paper are those reported in Thapa and Halvorsen (2013). 


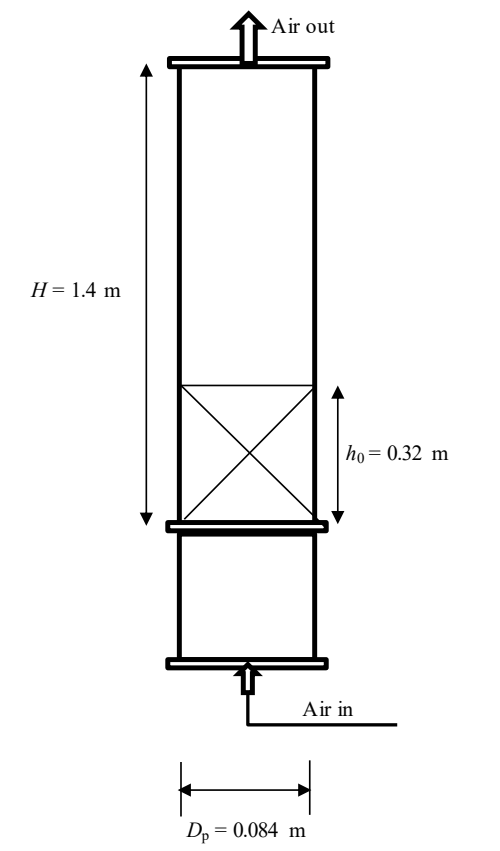

Figure 1. Physical Dimension of the fluidized bed column.

\section{Simulations}

The solution of the model described in Section 2 for the fluid-particle system is based on the finite volume method with staggered grids. The models are discretized in space using the first order upwind scheme, and in time based on the implicit method. The SIMPLE algorithm is used for the pressure-velocity coupling. The entire codes for the system are implemented and run in MATLAB. The properties of fluid and particles used in the computation are summarized in Table 1.

\subsection{Fluidized bed regimes}

In addition to simulating a bubbling fluidized bed, the transitions between different regimes for a fluidized bed are simulated using the 1D model. The flow transition from one regime to another depends on a number of factors. These include the bed particle size, the size distribution, the superficial gas velocity and the relative size between the bed height and the bed diameter. For a bed with Geldart B particles, the particle size and size distribution do not influence slugging in the bed (Baeyens and Geldart, 1974). As given in Yang (2003), slugging will occur if $\frac{h_{0}}{D_{h}}>2$. The minimum gas velocity for the onset of slugging can be obtained from (23) (Geldart, 1986) as used in Xie et al (2008).

$$
U_{\mathrm{ms}}=U_{\mathrm{mf}}+0.0016\left(60 D_{\mathrm{t}}^{0.175}-h_{\mathrm{mf}}\right)^{2}+0.07\left(g D_{\mathrm{t}}\right)^{0.5}
$$

Here, all the length units are expressed in $(\mathrm{cm})$, and $h_{\mathrm{mf}}$ is the bed height at minimum fluidization condition.

\subsection{Initial and Boundary Conditions}

Initially, the fluid pressure distribution is assumed hydrostatic, and the fluid velocity is considered uniform throughout the column, as described in Table 2. The inlet fluid pressure is assumed fixed, and it corresponds to the total weight of particles in the bed. Since the focus is on a bubbling bed, the outlet solid volume fraction is fixed to zero, while the fluid pressure at exit is taken to be atmospheric. The inlet boundary value for the solid volume fraction is dynamic, and then obtained appropriately from the void propagation equation.

\section{Results and Discussion}

Thapa and Halvorsen (2013) used the experimental rig described above to study the fluid-particle behaviour in a bed with particles having an average diameter of 350 $\mu \mathrm{m}$. The pressure drop values across the bed were recorded for different superficial gas velocities $(0.05-$ $0.40 \mathrm{~m} / \mathrm{s}$ ). The minimum fluidization velocity obtained by plotting the pressure drops against the superficial gas velocity, is about $0.15 \mathrm{~m} / \mathrm{s}$. This result shows that the theoretical minimum fluidization velocity specified in Table 1 for the bed, is about 14\% lower than the experimental value.

Table 1. Parameters for model computations.

\begin{tabular}{|l|l|l|}
\hline Parameters & Values & Units \\
\hline Particle diameter, $d_{\mathrm{p}}$ & 350 & $\mu \mathrm{m}$ \\
\hline Particle sphericity, $\emptyset_{\mathrm{s}}$ & 1.0 & - \\
\hline Particle density, $\rho_{\mathrm{s}}$ & 2500 & $\mathrm{~kg} / \mathrm{m}^{3}$ \\
\hline Gas density, $\rho_{\mathrm{g}}$ & 1.186 & $\mathrm{~kg} / \mathrm{m}^{3}$ \\
\hline Gas viscosity, $\mu_{\mathrm{g}}$ & $1.78 \times 10^{-5}$ & $\mathrm{~Pa} . \mathrm{s}$ \\
\hline Gas constant, $R$ & 0.287 & $\mathrm{~kJ} /(\mathrm{kg}-$ \\
& $\mathrm{K})$ \\
\hline Gas temperature, $T$ & 25 & ${ }^{0} \mathrm{C}$ \\
\hline Gas reference pressure, $P_{\text {ref }}$ & 1.0 & $\mathrm{bar}$ \\
\hline Initial bed height, $h_{0}$ & 0.32 & $\mathrm{~m}$ \\
\hline Initial solid volume fraction, $\varepsilon_{0}$ & 0.52 & - \\
\hline $\begin{array}{l}\text { Minimum fluidization velocity } \\
(19), U_{\text {mf }}\end{array}$ & 0.129 & $\mathrm{~m} / \mathrm{s}$ \\
\hline $\begin{array}{l}\text { Bed height at minimum } \\
\text { fluidization, } h_{\text {mf }}\end{array}$ & 0.32 & $\mathrm{~m}$ \\
\hline $\begin{array}{l}\text { Superficial gas velocity, } U_{0} \\
\text { Maximum solid }\end{array}$ & 0.05 & $\mathrm{~m} / \mathrm{s}$ \\
\hline $\begin{array}{l}\text { Mraction, } \varepsilon_{\text {smax }} \\
\text { folume }\end{array}$ & 0.63 & - \\
\hline Restitution coefficient, $e$ & 0.90 & - \\
\hline Simulation time step & 0.001 & $\mathrm{~s}$ \\
\hline No of cells & 125 & - \\
\hline
\end{tabular}


Table 2. Initial and boundary conditions.

\begin{tabular}{|l|c|}
\hline & $0 \leq z \leq h_{0}$ \\
Initial & $p_{\mathrm{g}}(0, z)=\varepsilon_{0} \rho_{\mathrm{s}} g\left(h_{0}-z\right)$ \\
Conditions & $\varepsilon_{\mathrm{s}}(0, z)=\varepsilon_{0}$ \\
& $h_{0}<z \leq H$ \\
& $P_{\mathrm{g}}(0, z)=0$ \\
& $\varepsilon_{\mathrm{s}}(0, z)=0$ \\
& $0 \leq z \leq H$ \\
& $u(0, z)=U_{0} / \varepsilon_{\mathrm{g}}$ \\
& $v(0, z)=0$ \\
\hline Inlet Boundary & $u(t, 0)=U_{0}$ \\
& $v(t, 0)=0$ \\
& $p_{\mathrm{g}}(t, 0)=\varepsilon_{0} \rho_{\mathrm{s}} g h_{0}$ \\
\hline Outlet & $p_{\mathrm{g}}(t, H)=0$ \\
Boundary & $\varepsilon_{\mathrm{s}}(t, H)=0$ \\
\hline
\end{tabular}

Figure 2 compares the simulated fluid pressure with the experimental data. The simulated results are obtained from the 1D model presented here and a 3D model reported by Thapa and Halvorsen (2013). As can be seen, the simulated data agree well with the experimental results at a height of $0.13 \mathrm{~m}$ above the distributor. At this height, the predictions from the 1Dmodel are better compared with the predictions from the $3 \mathrm{D}$ models. At the height of $0.23 \mathrm{~m}$, the $1 \mathrm{D}$ model results also agree very well with the results from the $3 \mathrm{D}$ model.

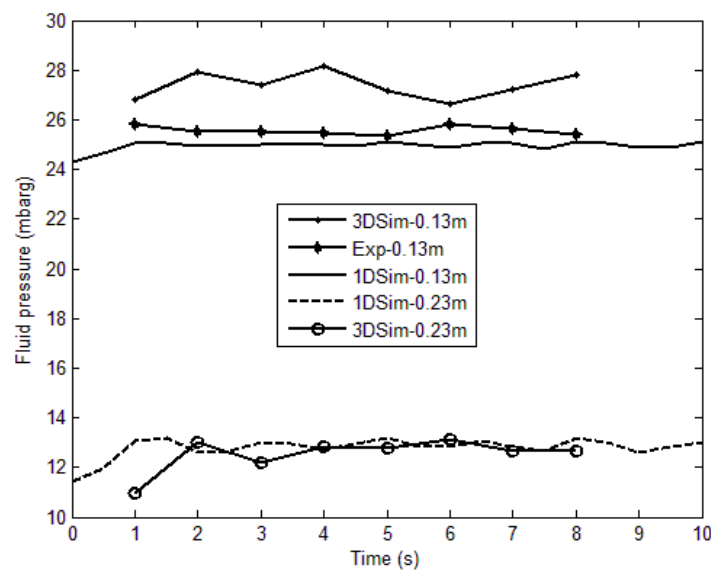

Figure 2. Evolution of fluid pressure at superficial gas velocity $0.18 \mathrm{~m} / \mathrm{s}$.

Figure 3 shows the time-averaged velocities of the fluid and particles for two different superficial gas velocities, $0.18 \mathrm{~m} / \mathrm{s}$ and $0.32 \mathrm{~m} / \mathrm{s}$. From these results, it can be seen that the fluid velocity at the exit of the column is slightly higher than the velocities at the inlet. This variation in the fluid velocity along the bed axis is probably due to changes in the fluid density along the bed height. The figure also shows that fluid velocities within the bed are higher than the inlet velocities, which could be due to lower flow area available for the gas as particles occupy space within this region. The variation of particle velocity within the bed at different gas velocities conforms to the solid movement pattern described by Kunii and Levenspiel (1991). Figure 4 gives the instantaneous solid volume fractions for the respective velocities after 5,10 and $20 \mathrm{~s}$. These results show that the movement of particles in the fluidized bed are more vigorous with higher superficial gas velocity.
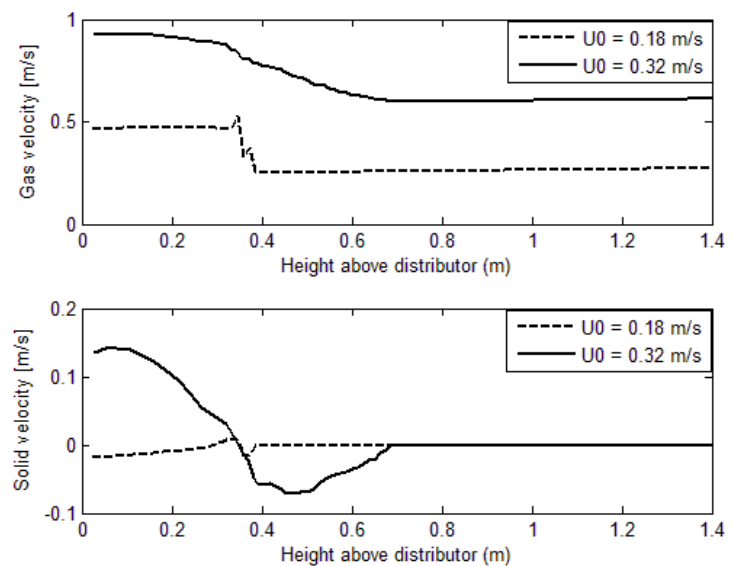

Figure 3. Time-averaged velocity profiles for fluid (upper plot) and particles (lower plot).
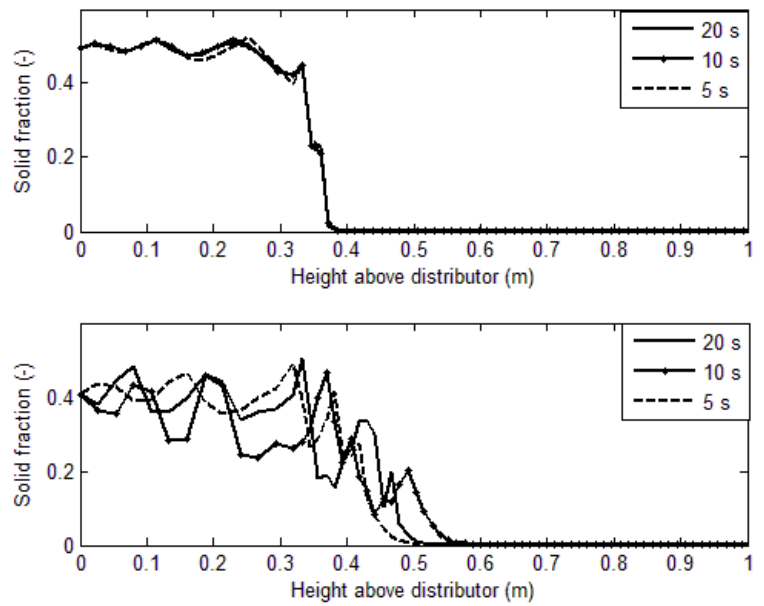

Figure 4. Instantaneous profile of solid fraction with superficial velocities $0.18 \mathrm{~m} / \mathrm{s}$ (upper plot) and $0.32 \mathrm{~m} / \mathrm{s}$ (lower plot).

The variation of average void fraction with superficial gas velocity within the dense region is shown in Figure 5. The average void fraction is obtained up to the height of $0.32 \mathrm{~m}$ above the distributor. The figure shows that the void fraction increases with increasing superficial gas velocity. It can also be seen that the bed transits into different regimes within different ranges of the superficial gas velocity. 


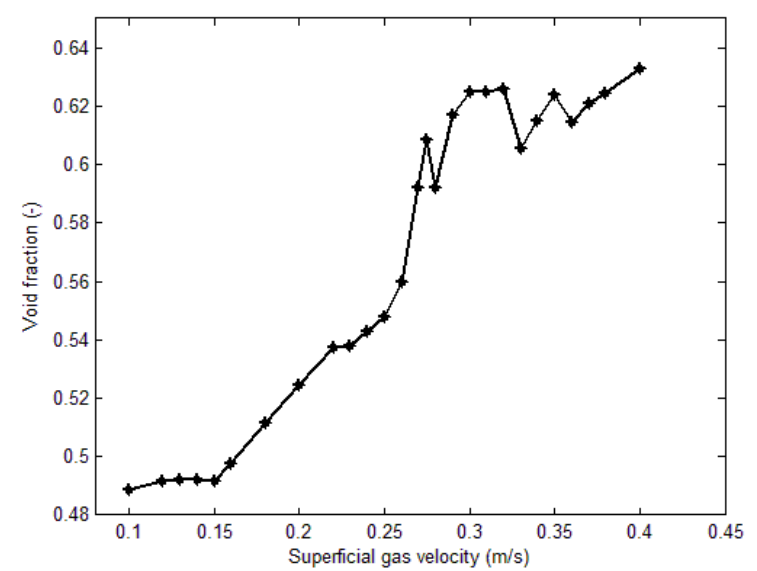

Figure 5. Variation of average bed void fraction with superficial velocity.

Four different flow regimes can be distinguished from Figure 5. Below $0.14 \mathrm{~m} / \mathrm{s}$, the bed's void fraction is about 0.49 . Within this region, the bed behaves like a fixed bed with all the particles retained within the dense bed. The abrupt increase in the void fraction after 0.14 $\mathrm{m} / \mathrm{s}$ indicates that the bed is fluidized. As expected for a Geldart B solid, the bed will begin to bubble when the velocity is above $0.14 \mathrm{~m} / \mathrm{s}$. Between $0.14 \mathrm{~m} / \mathrm{s}$ and 0.22 $\mathrm{m} / \mathrm{s}$, the void fraction increases linearly. Beyond 0.22 $\mathrm{m} / \mathrm{s}$, it increases exponentially with an increase in the gas velocity up to $0.27 \mathrm{~m} / \mathrm{s}$. Within this velocity, the bed is more agitated with fast-rising bubbles. From (23), the minimum gas velocity for the onset of slugging is about $0.26 \mathrm{~m} / \mathrm{s}$. Since $\frac{h_{0}}{D_{h}}=3.81(>2)$, there is possibility of slug flow in the bed when the superficial gas velocity is above $0.26 \mathrm{~m} / \mathrm{s}$. From Figure 5, it can be seen that the void fraction flattens out with a superficial gas velocity beyond $0.27 \mathrm{~m} / \mathrm{s}$. More so, the variation of void fraction above $0.27 \mathrm{~m} / \mathrm{s}$ fluctuates as the gas velocity increases, which shows that the bed is slugging. Thus, the velocity $0.27 \mathrm{~m} / \mathrm{s}$ is the gas velocity at onset of slugging based on this simulation. The fluctuation of the bed void fraction as the velocity increases could be because in a slug flow the bed does not have a clear defined height over which the averaging is taken. In comparison, similar phase changes have been experimentally observed in Sundaresan (2003) with beds of fine particles that can readily agglomerate. With the simulated minimum fluidization velocity being 0.14 $\mathrm{m} / \mathrm{s}$, compared with the experimental value of $0.15 \mathrm{~m} / \mathrm{s}$, and with the simulated gas velocity being $0.27 \mathrm{~m} / \mathrm{s}$ compared with the theoretical value of $0.26 \mathrm{~m} / \mathrm{s}$ at onset of slugging, it can be concluded that the 1D model predicts the bed flow behaviour reasonably well.

Figure 6 shows the profiles of solid volume fraction at velocities $0.08,0.20,0.25$ and $0.32 \mathrm{~m} / \mathrm{s}$, hence comparing the different flow regimes shown in Figure 5. The result shows that within the bubbling regime, the bed height expands by about $0.04 \mathrm{~m}$ (representing $12.5 \%$ ) above the height at the minimum fluidization.
The decrease in the solids fraction as the gas velocity increases is accompanied with a small fraction of particles in the freeboard. This keeps the mass of particles in the column balanced. In the solid region (fixed bed), the bed height is reduced below the settling bed height (about $0.32 \mathrm{~m}$, accompanied with an increase in solid fraction), owing to the fact that the bed is closely packed towards the maximum packing solid fraction of about 0.63 used in the simulation. The figure shows that in the slugging regime, the bed expands unevenly with some particles flowing into the freeboard up to a height of $0.6 \mathrm{~m}$. This shows that the bed height is not clearly defined within the slugging region, as can also be seen from Figure 7.

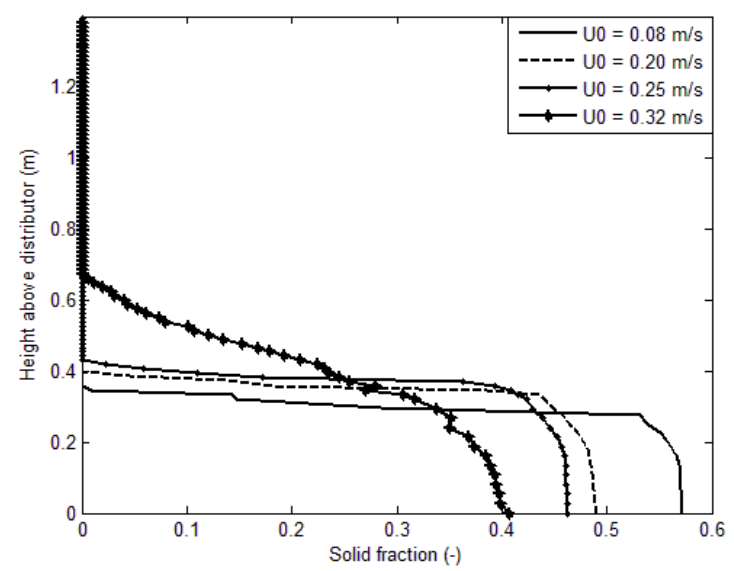

Figure 6. Simulated profile of solid fraction at different bed flow regimes.

Figure 7 shows the profile of solid fraction for some velocities within the slugging regime. Within the height interval $0.2-0.4 \mathrm{~m}$, the solid fractions at velocity 0.32 $\mathrm{m} / \mathrm{s}$ are lower than the corresponding solid fractions at velocity $0.36 \mathrm{~m} / \mathrm{s}$. This explains why the void fraction fluctuates with increasing superficial gas velocity within the slugging regime as given in Figure 5. Figure 7 also shows that the average solids volume fraction for the same range of velocities within the slugging regime is almost the same.

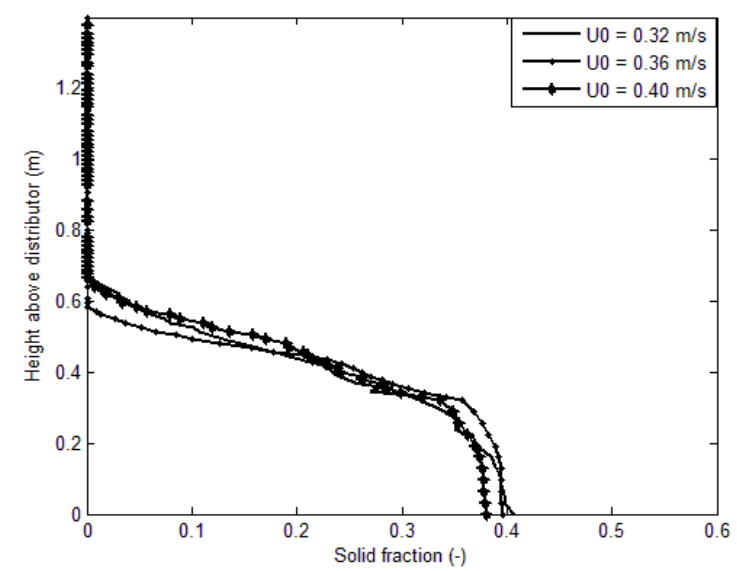

Figure 7. Simulated profile of solid fraction at different velocities within slugging regime. 


\section{Conclusions}

This paper presents a detailed one-dimensional model based on the Euler-Euler approach for predicting hydrodynamics of a bubbling fluidized bed. The solution algorithm includes a void propagation equation that accounts for the effect of fluid density variations. The method developed here is computational efficient, taking only 10 minutes computer time for simulation of a $20 \mathrm{~s}$ flow in the bed, against several hours required in a 3D model computation.

Qualitatively, the results show that the 1D model predicts the different regimes of a fluidized bed. The simulated minimum fluidization velocity agrees well with the experimental data, and the value of gas velocity at the onset of slugging compares well with the value obtained from the empirical expression proposed by Geldart (1986).

Further work will include full validation of the 1D model against a 3D model results and analysis of sensitivity of the model to different parameters.

\section{References}

J. Baeyens and D. Geldart. An Investigation into Slugging Fluidized Beds. Chemical Engineering Science, 29: 255 265, 1974.

H. M. Benzarti and H. Bournot. Drag Models for Simulation Gas-Solid Flow in the Bubbling Fluidized Bed of FCC Particles. International Journal of Chemical, Molecular, Nuclear, Materials and Metallurgical Engineering, 6 (1), 2012.

C. T. Crowe, J. D. Schwarzkopf, M. Sommerfeld, and Y. Tsuji. Multiphase Flows with Droplets and Particles, 2nd ed., Taylor \& Francis Group, Boca Raton London, New York, USA, 2012.

J. F. Davidson and D. Harrison. Fluidized Particles, Cambridge University Press, New York, 1965.

S. Ergun. Fluid Flow through Packed Column. Chemical Engineering Progress, 48: 89 - 94, 1952.

D. Geldart (Ed.). Gas Fluidization Technology, 1st ed., John Wiley \& Sons, Ltd., pp. 53 - 97, Chap. 4, 1986.

D. Gidaspow. Multiphase Flow and Fluidization: Continuum and Kinetics Theory Descriptions, Academic Press Inc., San Diego, California, USA, 1994.
D. Kunii and O. Levenspiel. Fluidization Engineering, 2nd ed Butterworth - Heinemann, Washington Street, USA, 1991.

D. Lathowers and J. Bellan. Modeling of Dense Gas-Solid Reactive Mixtures Applied to Biomass Pyrolysis in a Fluidized Bed. In Proceedings of the 2000 US, DOE Hydrogen Program Review, NREL/CP-570-28890, USA, 2000.

P. Li, X. Lan, C. Xu, G. Wang, C. Lu and J.Gao. Drag Models for Simulating Gas-Solid Flow in the Turbulent Fluidization of FCC Particles. Particuology, 7: 269 - 277, 2009.

J.D. Silva. Numerical Modelling of the Fluid Dynamics in a Bubbling Fluidized Bed Biomass Gasifier. Journal of Petroleum and Gas Engineering, 3 (3): 35 - 40, 2012.

J. Solsvik, Z. Chao, and H. A. Jakobsen. Modeling and Simulation of Bubbling Fluidized Bed Reactors using a Dynamic One-dimensional Two-Fluid Model: The Sorption-Enhanced Steam-Methane Reforming Process. Advances in Engineering Software, 80: 156 - 173, 2015.

S. Sundaresan. Instabilities in Fluidized Beds. Annual Review of Fluid Mechanics, 35: 63 - 88, 2003.

M. Syamlal. MFIX Documentation Numerical Technique. Report, Department of Energy, Federal Energy Technology Center, DOE/MC 31346-5824, USA, 1998.

F. Taghipour, N. Ellis, and C. Wong. Experimental and Computational Study of Gas-Solid Fluidized Bed Hydrodynamics. Chemical Engineering Science, 60: 6857 $-6867,2005$.

R.K. Thapa and B.M. Halvorsen. Study of Flow Behaviour in Bubbling Fluidized Bed Biomass Gasification Reactor using CFD Simulation. In Proceedings of the 14th International Conference on Fluidization from Fundamentals to Products, Eds. ECI Symposium Series, Volume, 2013.

C.Y. Wen and Y.H. Yu. A Generalized Method for Predicting the Minimum Fluidization Velocity. AIChE J., 12: $610-612,1966$.

N. Xie, F. Battaglia, and S. Pannala. Effects of Using Two- Versus Three-Dimensional Computational Modeling of Fluidized Beds: Part I, Hydrodynamics. Powder Technology, 182: 1 - 13, 2008.

W.C. Yang (Ed.). Handbook of Fluidization and FluidParticle Systems, Marcel Dekker, Inc., 2003. 